\title{
In-vitro inhibition of the block to polyspermy of hamster eggs by tertiary amine local anaesthetics
}

\author{
K. K. Ahuja \\ Marshall Laboratory, Physiological Laboratory, University of Cambridge, \\ Cambridge CB2 3EG, U.K.
}

\begin{abstract}
Summary. When freshly ovulated hamster eggs ( $16 \mathrm{~h}$ after hCG) were incubated at $37^{\circ} \mathrm{C}$ in the presence of local anaesthetics, the extrusion of the second polar body was inhibited in differing proportions of eggs, depending on the concentration of drug and the age of eggs. Insemination of procaine $\left(3 \times 10^{-3} \mathrm{M}\right)$ - and tetracaine $(2 \times$ $10^{-4} \mathrm{M}$ )-treated eggs with capacitated spermatozoa in vitro resulted in $\sim 80 \%$ of eggs showing multiple penetration compared with $\sim 20 \%$ for controls, indicating that local anaesthetics interfere with the block to polyspermy in the egg. This effect was reversed by raising the concentration of $\mathrm{Ca}^{2+}$, but not $\mathrm{Mg}^{2+}$, during treatment with the drug or washing the drug-loaded eggs in $\mathrm{Ca}^{2+}$-containing medium. When the treatment of eggs was carried out at $4^{\circ} \mathrm{C}$, no such inhibition of the block to polyspermy was observed. The extrusion of cortical granules was delayed by procaine, although the rate of fertilization was not affected. The results provide evidence to support the belief that the initiation of the block to polyspermy in the hamster is dependent on $\mathrm{Ca}^{2+}$-triggered release of cortical granules.
\end{abstract}

\section{Introduction}

After fertilization the egg is transformed from a semiquiescent state to an activated state for which the earliest visible indications are the breakdown of cortical granules and the resumption of the second meiotic division. Depending upon the species, the subsequent development of a block to multiple penetration by spermatozoa involves changes in the zona pellucida, oolemma or both. The contents of cortical granules, such as trypsin-like enzyme or peroxidase-like enzyme, are believed to be responsible for these changes in the physiological properties of egg investments. The precise biochemical mechanism of cortical granule breakdown and subsequent influences on the egg investments are, however, not well understood (Austin, 1977; Edwards, 1980).

The use of tertiary amine local anaesthetics provides a way of investigating the changes in membrane properties during fertilization. In addition to their anaesthetic properties on excitable cell membranes (Seeman, 1972), they affect a large number of cellular processes (reviewed in Nicolson, 1976). Due to their amphipathic structure, they partition into cellular membranes and interact with membrane lipids, particularly anionic phospholipids, and produce molecular disorder in bilayers. As a result, a large number of membrane-dependent cellular processes, including the sperm acrosome reaction (Collins \& Epel, 1977) and the exocytosis of cortical granules (Vacquier, 1975) in the sea urchin, Stronglyocentrotus purpuratus, are affected. The present study describes preliminary attempts using local anaesthetics to understand the fertilization-associated changes in the hamster egg membrane, particularly those associated with the formation of the second polar body and the block to polyspermy. 


\section{Materials and Methods}

\section{Culture media}

Three kinds of media were used. (1) For the drug treatment and regular handling of eggs, a

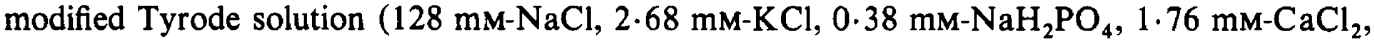

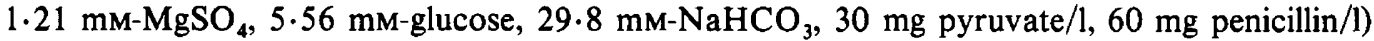
with $2 \mathrm{mg}$ bovine serum albumin/ml was used (Medium I). (2) In the experiments in which high concentrations of calcium were used, thus necessitating a medium that keeps a stable $\mathrm{pH}$ while in contact with air, the $\mathrm{NaHCO}_{3}$ in Medium I was replaced with Hepes buffer (Flow Laboratories, London). The $\mathrm{pH}$ of the resulting medium was adjusted to 7.2 with $\mathrm{NaOH}$, and the osmolarity to 290-300 mosmol by altering the concentration of $\mathrm{NaCl}$ (Medium II). (3) The modified Tyrode solution plus $15 \%(\mathrm{v} / \mathrm{v})$ heat-activated human serum was used for the in-vitro fertilization of hamster eggs (Medium III).

\section{Collection, drug treatment and in-vitro fertilization of oocytes}

Unless otherwise indicated procaine hydrochloride (Sigma, London) or tetracaine hydrochloride (Sigma) were dissolved in Medium I at the concentrations indicated and $2 \mathrm{ml}$ medium were dispensed into an embryological dish and gassed with $5 \% \mathrm{CO}_{2}$ in air. Freshly ovulated ( $15 \mathrm{~h}$ after injection of 30 i.u. hCG) hamster eggs were freed of cumulus cells and transferred to this dish; incubation was allowed to continue for $90 \mathrm{~min}$ at $37^{\circ} \mathrm{C}$ in $5 \% \mathrm{CO}_{2}$ in air. Then the eggs were taken out, rinsed with 4 changes in drug-free Medium I for about 1 min and inseminated with spermatozoa already capacitated by incubation in Medium III for $4.5 \mathrm{~h}$ with cumulus cells. In all the experiments eggs from different females were pooled and then distributed randomly to different treatment groups. The techniques for collection of eggs and in-vitro fertilization have been described previously (Ahuja \& Tzartos, 1981).

The main criterion for fertilization was the presence of a swollen sperm head in the egg which could easily be visualized under the phase-contrast microscope. The presence or absence of cortical granules in the fertilized eggs could also be established by examination with phase-contrast microscopy and an oil-immersion objective. The vital staining technique of Fukuda \& Chang (1978), using Bismark Brown, was sometimes used to determine whether or not cortical granules had broken down. When the normal eggs were examined after $90 \mathrm{~min}$, $90-100 \%$ fertilization was observed and about $80 \%$ of the fertilized eggs were monospermic.

\section{Results}

\section{Second polar body formation}

When incubated for $90 \mathrm{~min}$ in Medium I, $<50 \%$ of freshly ovulated eggs ( $16 \mathrm{~h}$ after hCG) exhibited extrusion of the second polar body. With increasing post-ovulatory age, however, the percentage of eggs showing a second polar body at the end of the incubation period increased, with $100 \%$ extrusion occurring for eggs collected at $23 \mathrm{~h}$ after hCG injection. Procaine and tetracaine inhibited the formation of second polar body in differing proportions of eggs, depending on the concentration of drug and the age of eggs. A substantially higher concentration of anaesthetics was required to suppress second polar body formation in older eggs. For instance, $5 \times 10^{-4} \mathrm{M}$-procaine allowed second polar body extrusion in only $29.2 \%$ of freshly ovulated eggs ( $16 \mathrm{~h}$ after hCG), but $>3 \times 10^{-3} \mathrm{M}$-procaine was required to achieve this result with eggs acquired $23 \mathrm{~h}$ after hCG (Table 1). 
Table 1. Inhibition of the formation of second polar body of hamster eggs by local anaesthetics (dissolved in Medium I)

\begin{tabular}{llccc}
\hline & & \multicolumn{3}{c}{$\begin{array}{c}\text { Eggs (\%) showing 2nd polar body after 90 min } \\
\text { incubation (proportion)* }\end{array}$} \\
\cline { 3 - 5 } Treatment & $\begin{array}{c}\text { Conc. } \\
\text { (M) }\end{array}$ & $16 \mathrm{~h}$ & $19 \mathrm{~h}$ & $23 \mathrm{~h}$ \\
\hline Control & - & $45.2(56 / 124)$ & $71.0(59 / 83)$ & $100(67 / 67)$ \\
Procaine & $5 \times 10^{-4}$ & $29.2(21 / 71)$ & $65.3(35 / 52)$ & $100(36 / 36)$ \\
& $1 \times 10^{-3}$ & $28.3(15 / 53)$ & $59.0(28 / 47)$ & $81.2(26 / 32)$ \\
& $3 \times 10^{-3}$ & $7.5(4 / 53)$ & $24.4(11 / 41)$ & $38 \cdot 1(16 / 42)$ \\
Tetracaine & $7.5 \times 10^{-6}$ & $42.4(14 / 33)$ & $65.0(26 / 40)$ & $100(52 / 52)$ \\
& $1 \times 10^{-3}$ & $16.2(11 / 68)$ & $30.8(20 / 65)$ & $51 \cdot 0(24 / 47)$ \\
& $2.5 \times 10^{-4}$ & $0(0 / 44)$ & $10.0(5 / 50)$ & $19.2(9 / 47)$ \\
\hline
\end{tabular}

* There were 5-8 replicates for the control group and 4-5 for the experimental groups.

\section{Block to polyspermy}

Pretreatment of freshly ovulated hamster eggs for 90 min with procaine and tetracaine did not cause any visible deleterious effects on eggs. After cleaning and insemination for $90 \mathrm{~min}$ there was a high percentage of fertilization. Swollen sperm heads were observed in the oocytes of the control and the experimental groups (Table 2).

Table 2. In-vitro fertilization of hamster eggs treated with local anaesthetics (dissolved in Medium I)

\begin{tabular}{lccccc}
\hline Treatment & $\begin{array}{c}\text { No. of } \\
\text { replicates }\end{array}$ & $\begin{array}{c}\text { Fertilization \% } \\
\text { (proportion) }\end{array}$ & $\begin{array}{c}\text { Fertilized eggs } \\
\text { showing perivitelline } \\
\text { spermatozoa (\%) }\end{array}$ & $\begin{array}{c}\text { Polyspermy* } \\
\text { (\%) }\end{array}$ & $\begin{array}{c}\text { Mean no. of } \\
\text { spermatozoa/ } \\
\text { polyspermic egg }\end{array}$ \\
\hline Control & 16 & $82.3(182 / 221)$ & 8.5 & 18.7 & 2.45 \\
Procaine (M) & & & & & \\
$\quad 3 \times 10^{-3}$ & 8 & $80.0(96 / 120)$ & 26.0 & 79.2 & 3.1 \\
$5 \times 10^{-3}$ & 5 & $74.8(89 / 119)$ & 32.4 & 83.2 & 3.8 \\
Tetracaine (M) & & & & & \\
$7.5 \times 10^{-5}$ & 5 & $78.2(68 / 87)$ & 16.1 & 33.0 & 2.47 \\
$2.0 \times 10^{-4}$ & 7 & $80.7(84 / 104)$ & 58.8 & 82.1 & 2.61 \\
\hline
\end{tabular}

*\% of fertilized eggs showing multiple sperm penetration.

Many more eggs treated with local anaesthetics were penetrated by more than one spermatozoon than were untreated eggs, though even these showed a much higher incidence of polyspermy than is seen with fertilization in vivo (presumably because of the higher concentration of spermatozoa used in vitro). After treatment with procaine at both doses and tetracaine at $2 \times 10^{-4} \mathrm{M}$, multiple penetration by spermatozoa was seen in about $80 \%$ of the fertilized eggs. Compared with the control group, the average number of spermatozoa per egg in polyspermic eggs was slightly higher in the experimental group. The numbers of eggs with perivitelline spermatozoa were also greater after treatment with anaesthetics; tetracaine seemed to be more effective in this respect. Higher concentrations of tetracaine $\left(5 \times 10^{-4} \mathrm{M}\right)$ and procaine $\left(7.5 \times 10^{-3} \mathrm{M}\right)$ reduced sperm-egg fusion drastically (data not shown).

It was possible that trace amounts of procaine and tetracaine absorbed by the eggs during treatment and later released could change the overall environment of the culture droplets and affect the fertilizing capability of spermatozoa. Capacitated spermatozoa were therefore treated with 2.5-5.0 $\times 10^{-4} \mathrm{M}$-procaine for 15-30 min before allowing them to interact with fresh eggs. 
When checked after 90 min, no significant change in the level of polyspermy was observed: in 2 different experiments, 37 out of 39 eggs were fertilized, 5 of which were bispermic and one tetraspermic.

\section{Role of calcium in the inhibition of the block to polyspermy by local anaesthetics}

The reversibility of the effects of local anaesthetics was tested in two experiments. In Exp. 1, eggs were treated with procaine or tetracaine as described above then washed for $60 \mathrm{~min}$ in Medium I (containing $1.71 \mathrm{~mm}$-calcium) or calcium-free medium, before transferring them to the fertilization droplets. In Exp. 2, the concentration of extracellular calcium was raised to $10 \mathrm{~mm}$ during the $90-\mathrm{min}$ period of drug treatment.

Experiment 1 . Incubation of freshly ovulated hamster eggs in Medium I for a total period of $2.5 \mathrm{~h}$ did not reduce the proportion of eggs fertilized. [This observation is consistent with recent reports in the mouse in which the penetrability of mouse eggs was not lost during a 2-h preincubation period (Fraser, 1979).] Extended washing of the drug-loaded eggs in this medium for $60 \mathrm{~min}$ reversed the effects of the anaesthetics and reduced the incidence of polyspermy to levels equivalent to, or lower than those of controls. When eggs were washed in medium lacking calcium, however, there was no significant change in the proportion of polyspermic eggs (Table 3). Fertilized eggs of all groups showed extrusion of cortical granules.

Table 3. Restoration of the block to polyspermy in hamster eggs treated with local anaesthetics by washing for $60 \mathrm{~min}$ in drug-free medium

\begin{tabular}{llcccc}
\hline Treatment & Washing medium & $\begin{array}{c}\text { Washing time } \\
(\mathrm{min})\end{array}$ & $\begin{array}{c}\text { No. of } \\
\text { replicates }\end{array}$ & $\begin{array}{c}\text { Fertilization \% } \\
\text { (proportion) }\end{array}$ & $\begin{array}{c}\text { Polyspermy } \\
(\%)\end{array}$ \\
\hline Control & Medium I & 60 & 5 & $70.7(46 / 65)$ & 23.9 \\
Procaine & Medium I & 1 & 3 & $84.6(33 / 39)$ & 81.8 \\
$\left(3 \times 10^{-3} \mathrm{M}\right)$ & Medium I & 60 & 4 & $74.3(52 / 70)$ & 25.0 \\
& $\mathrm{Ca}^{2+}$-free Medium I & 60 & 3 & $66.2(45 / 68)$ & 66.7 \\
Tetracaine & & & & & \\
$\left(2 \times 10^{-4} \mathrm{M}\right)$ & Medium I & 1 & 4 & $77.9(53 / 68)$ & 69.8 \\
& Medium I & 60 & 4 & $66.7(40 / 60)$ & 17.5 \\
& $\mathrm{Ca}^{2+}$-free Medium I & 60 & 4 & $65.2(30 / 46)$ & 66.7 \\
\hline
\end{tabular}

Experiment 2. The presence of $10 \mathrm{~mm}$-calcium in the medium containing a local anaesthetic did not reduce the proportion of eggs fertilized, but it reversed the effects of procaine and tetracaine, the percentage of eggs showing multiple sperm penetration being similar to that of the control eggs (Table 4). Magnesium at $10 \mathrm{~mm}$ did not neutralize the effect of procaine.

Table 4. Effects of increased calcium levels and local anaesthetics on the incidence of polyspermy in hamster eggs

\begin{tabular}{lccccc}
\hline Treatment & Divalent cation & $\begin{array}{c}\text { Conc. } \\
(\mathrm{mM})\end{array}$ & $\begin{array}{c}\text { No. of } \\
\text { replicates }\end{array}$ & $\begin{array}{c}\text { Fertilization \% } \\
\text { (proportion) }\end{array}$ & $\begin{array}{c}\text { Polyspermy } \\
(\%)\end{array}$ \\
\hline Control & $\mathrm{Ca}^{2+}$ & 0 & 4 & $71.9(41 / 57)$ & 17.0 \\
& $\mathrm{Ca}^{2+}$ & $1 \cdot 71$ & 4 & $73.2(41 / 56)$ & $15 \cdot 5$ \\
Procaine & $\mathrm{Ca}^{2+}$ & 0 & 4 & $75 \cdot 7(47 / 62)$ & $74 \cdot 5$ \\
$\left(5 \times 10^{-3} \mathrm{M}\right)$ & $\mathrm{Ca}^{2+}$ & $1 \cdot 71$ & 3 & $76.5(39 / 51)$ & 77.0 \\
& $\mathrm{Ca}^{2+}$ & 10 & 3 & $75 \cdot 7(50 / 66)$ & 26.0 \\
& $\mathrm{Mg}^{2+}$ & 10 & 3 & $70.4(31 / 44)$ & 64.0 \\
Tetracaine & $\mathrm{Ca}^{2+}$ & $1 \cdot 71$ & 4 & $77.0(47 / 61)$ & 76.6 \\
$\left(2 \times 10^{-4} \mathrm{M}\right)$ & $\mathrm{Ca}^{2+}$ & 10 & 4 & $73.8(39 / 53)$ & 15.3 \\
\hline
\end{tabular}

Local anaesthetics were dissolved in Medium II containing no $\mathrm{Ca}^{2+}(0 \mathrm{~mm})$, normal levels of $\mathrm{Ca}^{2+}$ $(1.71 \mathrm{~mm})$ or high levels of $\mathrm{Ca}^{2+}(10 \mathrm{mM})$ or $\mathrm{Mg}^{2+}(10 \mathrm{mM})$. Treatment of eggs was then carried out as outlined in 'Materials and Methods'. 
Effect of temperature on the inhibition of the block to polyspermy by local anaesthetics

A comparison was made between the effects of local anaesthetics at 4 and $37^{\circ} \mathrm{C}$. Eggs were checked for polyspermic fertilization $90 \mathrm{~min}$ after insemination. The incubation of control eggs at $4^{\circ} \mathrm{C}$ did not alter the proportion of eggs subsequently fertilized at $37^{\circ} \mathrm{C}$ (Table 5). The block to polyspermy was also unaffected. The lower temperature suppressed the action of procaine since the incidence of polyspermy in procaine-treated eggs was the same as in controls. However, fertilization rates were unchanged.

Table 5. Effect of temperature on the inhibition of the block to polyspermy by local anaesthetics dissolved in Medium II

\begin{tabular}{lccc}
\hline Treatment & $\begin{array}{c}\text { Temperature } \\
\left({ }^{\circ} \mathrm{C}\right)\end{array}$ & $\begin{array}{c}\text { Fertilization \% } \\
(\text { proportion) }\end{array}$ & $\begin{array}{c}\text { Polyspermy } \\
(\%)\end{array}$ \\
\hline Control & 4 & $80.0(40 / 50)$ & $20 \cdot 0$ \\
Procaine $\left(3 \times 10^{-3} \mathrm{M}\right)$ & 4 & $76.9(50 / 65)$ & 28.0 \\
Tetracaine $\left(2 \times 10^{-4} \mathrm{M}\right)$ & 4 & $80 \cdot 1(64 / 79)$ & 29.4 \\
Control & 37 & $70.2(33 / 47)$ & $15 \cdot 2$ \\
Procaine $\left(3 \times 10^{-3} \mathrm{M}\right)$ & 37 & $79.5(35 / 44)$ & 80.0 \\
\hline
\end{tabular}

* The results are values for 4 replicates each.

\section{Kinetics for sperm penetration and cortical granule release}

Penetration of control and experimental eggs by capacitated spermatozoa began between 40 and $50 \mathrm{~min}$ after insemination, and the majority of eggs were fertilized 70-80 min after the transfer of eggs to fertilization droplets (Table 6). Cortical granules began to be released from control eggs soon after penetration, and the majority of control eggs had extruded their cortical granules by $70 \mathrm{~min}$. In eggs treated with procaine the cortical granules were not rapidly released in many eggs. This may have allowed more spermatozoa to penetrate and fuse with the egg membrane until about $90 \mathrm{~min}$ (Table 6).

Table 6. Time relations of sperm penetration and cortical granule release in normal and procaine treated $\left(5 \times 10^{-3} \mathrm{M}\right)$ eggs $\mathrm{s}^{*+}$

\begin{tabular}{|c|c|c|c|c|c|c|}
\hline \multirow{2}{*}{$\begin{array}{l}\text { Time } \\
(\min )\end{array}$} & \multicolumn{2}{|c|}{ Fertilization (\%) } & \multicolumn{2}{|c|}{ Polyspermy (\%) } & \multicolumn{2}{|c|}{ Cortical granules } \\
\hline & Control & Treated & Control & Treated & Control & Treated \\
\hline 40 & $2 \cdot 0$ & 0 & 0 & 0 & ++++ & ++++ \\
\hline 50 & 20.6 & 25.8 & $8 \cdot 3$ & $10 \cdot 0$ & ++++ & ++++ \\
\hline 60 & $60 \cdot 0$ & 55.6 & 20.4 & $36 \cdot 5$ & ++ & ++++ \\
\hline 70 & $69 \cdot 3$ & 73.4 & 16.4 & $80 \cdot 5$ & + & ++++ \\
\hline 80 & $72 \cdot 6$ & $84 \cdot 3$ & 22.8 & 79.0 & + & +++ \\
\hline 90 & 80.2 & $76 \cdot 4$ & 23.4 & 82.8 & + & + to + \\
\hline
\end{tabular}

* Eggs were treated with procaine dissolved in Medium I, rinsed and then inseminated with capacitated spermatozoa in Medium III.

$\dagger$ The results are means from 4 replicates with $>40$ eggs for each group.

\section{Discussion}

This study demonstrates that the frequency of second polar body extrusion, an early indication of egg activation, can be reduced by the local anaesthetics, procaine and tetracaine. The activation of mammalian oocytes is believed to be triggered by changes in the concentration of intracellular calcium (Whittingham, Siracusa \& Fulton, 1978) and is affected by alteration in the 
extracellular levels (Surani \& Kaufman, 1977; Uehara \& Yanagimachi, 1977). The calcium flux across the membrane is inhibited in the presence of local anaesthetics and they are also known to disrupt the cell cytoskeleton system by displacing $\mathrm{Ca}^{2+}$ from the membranes (Seeman, 1972; Nicolson, 1976). It appears from the present study that a chain of calcium-triggered intracellular reactions begins soon after ovulation and fertilization or parthenogenetic activation leads to the formation of the second polar body. At any particular stage this system or chain of responses can be slowed down or stopped by local anaesthetics, but as each response progresses, higher concentrations of the drug are required.

Treatment of hamster eggs with local anaesthetics, in concentrations known to affect membrane functions, inhibited the block to polypsermy in vitro. Procaine and tetracaine reversibly delayed the release of cortical granules which are considered to underlie the block to polyspermy in the hamster (Austin, 1977). A wide variety of other exocytotic systems are similarly reversibly inhibited by local anaesthetics (Kazimierczak, Peret \& Maslinski, 1976; Collins \& Epel, 1977). The precise mechanism of inhibition is unknown.

Siracusa, Whittingham, Cadonesu \& De Felici (1978) showed that local anaesthetics cause parthenogenetic activation of freshly ovulated oocytes. Their results then may appear in conflict with those of the present study, but in fact the very different experimental conditions employed probably account for the discrepancy. Siracusa et al. (1978) used as much as 1000 -fold lower concentration of drugs, employed mice as experimental animals, incubated eggs for $6 \mathrm{~h}$ and scored for pronuclear formation. Depending on concentration used, the tertiary amine local anaesthetics are known to have varied effects in a particular cell system. At millimolar concentrations of procaine, sea-urchin eggs (Vacquier, 1975), starfish eggs (Cloud \& Schuetz, 1979) and hamster eggs (present study) are affected similarly.

The cortical reaction involves the fusion of the membranes of the cortical granules with the plasma membranes of the egg. Membrane fusion is a $\mathrm{Ca}^{2+}$-dependent process; $\mathrm{Ca}^{2+}$ binding sites have been located ultrastructurally in the membranes of cortical granules of the sea-urchin egg (Caradasis, Schuel \& Herman, 1978) and the fusing sites on the cortical and plasma membranes undergo intrinsic changes during fusion (Pollock, 1978). Local anaesthetics are capable of interfering with membrane fusion by their solubility in membrane phospholipids and ability to displace calcium ions from their binding sites (Nicolson, 1976; Poste \& Pasternak, 1979). In the hamster egg, however, membrane fusion per se does not seem to be inhibited because sperm-egg fusion was readily observed in the anaesthetic-treated eggs. The persistence of cortical granules in drug-loaded eggs may be due to other reasons (see below).

Local anaesthetics are also known to disrupt the cytoplasmic microfilament system, by interfering with intracellular $\mathrm{Ca}^{2+}$ concentration or by direct action (Nicolson, 1976). It is possible that they prevent the close approximation of cortical and plasma membranes $(<15 \mathrm{~nm})$, an essential prerequisite for membrane fusion (Poste \& Allison, 1973). The cortical microfilaments may have a functional relationship with the cortical granules and so be involved in their expulsion, although in one study Cytochalasin B did not cause polyspermy in the mouse (Niemierko \& Korman, 1976). Another possibility is that, like nicotine, local anaesthetics also cause a rapid rise in intracellular pH (Johnson, Epel \& Paul, 1976). The block to polyspermy in the hamster egg becomes weaker at higher extracellular pH (Bavister, 1969).

The presence of high levels of $\mathrm{Ca}^{2+}$ in the medium reversed the inhibitory effects of local anaesthetics on the extrusion of cortical granules, an observation consistent with studies carried out on exocytosis in other cell systems (Kazimierczak et al., 1976; Collins \& Epel, 1977). A raised external calcium concentration is known to reverse the inhibition of electrical changes in excitable cell membranes by anaesthetics (Seeman, Chen, Chan-Wong \& Staiman, 1974). Elevation of the external $\mathrm{Ca}^{2+}$ level might also help to decrease the binding of cationic anaesthetics to membranes, to levels below the threshold concentrations necessary for their action. 
Local anaesthetics are also known to act by increasing membrane fluidity (Sheetz \& Singer, 1974), an effect that is easily reversed by lowering the temperature (Singer, 1974). A large number of membrane-bound enzymes, which are vulnerable to local anaesthetics at normal temperature, may be protected in a membrane made more rigid at low temperature (Seeman, 1973). The cortical reaction and subsequent changes in the egg investments are believed to involve the actions of several enzymes including ovoperoxidase (Schmell \& Gulyas, 1980), which in sea-urchin eggs is susceptible to procaine inhibition (Foerder \& Shapiro, 1977). It is therefore possible that in the hamster egg the actions of procaine and tetracaine are mediated through the destruction or inactivation of such enzymes. When treated at lower temperature, hamster eggs showed no inhibition of the block to polyspermy, presumably because all the enzymes associated with the cortical reaction and subsequent changes in the zona pellucida were protected against the actions of procaine and tetracaine.

On the basis of the demonstration that zona-free fertilized hamster eggs can be refertilized if inseminated in vitro, Barros \& Yanagimachi (1972) concluded that the hamster egg membrane remains unchanged during and after fertilization. This study did not, however, rule out the possibility that in the hamster the egg membrane undergoes some intrinsic changes at fertilization which are rapid and transient, unlike those in the mouse. In view of the present findings, it seems reasonable to suggest that after fertilization the hamster egg membrane could alter quickly. These changes could be due to alterations in the fluidity of the egg membrane (Johnson \& Edidin, 1978) or could be electrical in nature and resemble the 'fast block' of sea-urchin eggs which is also rapid, transient and electrical (Jaffe, 1976). As in mouse (Wolf \& Hamada, 1979) and sea-urchin eggs (Jaffe, 1976) these changes may not involve the actions of the contents of cortical granules. Whatever the biochemical nature of the block to polyspermy, local anaesthetics, by virtue of their ability to increase the fluidity of the membrane and inhibit any electrical changes, are capable of suppressing these changes in the egg membrane, thus leading to polyspermic fertilization.

I thank Professor C. R. Austin, Dr R. G. Edwards and Dr A. Surani for helpful advice and criticism and Miss Anna Gustafson for help with the preparation of the manuscript. This work was supported by a St John's College (Cambridge) Research Studentship and a Ford Foundation Grant.

\section{References}

Ahuja, K.K. \& Tzartos, S.J. (1981) Investigation of sperm receptors in the hamster zona pellucida by using univalent (Fab) antibodies to hamster ovary. $J$. Reprod. Fert. 61, 257-264.

Austin, C.R. (1977) Spermatozoa and ova: the role of membranes in the fertilization process. In Mammalian Cell Membranes, pp. 206-230. Eds J. D. Jamieson \& D. W. Robinson. Butterworths, New York.

Barros, C. \& Yanagimachi, R. (1972) Polyspermy preventing mechanism in the golden hamster egg. $J$. exp. Zool. 180, 251-266.

Bavister, B.D. (1969) Environmental factors important for in vitro fertilization in the hamster. J. Reprod. Fert. 18, 544-545, Abstr.

Caradasis, C.A., Schuel, H. \& Herman, L. (1978) Ultrastructural localization of calcium in unfertilized sea-urchin eggs. J. Cell. Sci. 31, 101-115.
Cloud, J.G. \& Schuetz, A.W. (1979) 1-Methyladenine induction of oocyte (starfish) maturation: inhibition by Procaine and its $\mathrm{pH}$ dependency. J. exp. Zool. 210, 11-16.

Collins, F. \& Epel, D. (1977) The role of calcium ions in the acrosome reaction of sea-urchin sperm. Expl Cell Res. 106, 211-222.

Edwards, R.G. (1980) Fertilization. In Conception in the Human Female, Ch. 8, pp. 573-651. Academic Press, London.

Foerder, C.A. \& Shapiro, B.M. (1977) Release of ovoperoxidase from sea urchin eggs harden the fertilization membrane with tyrosin cross-links. Proc. natn. Acad. Sci. U.S.A. 74, 4212-4218.

Fraser, L.R. (1979) Accelerated mouse sperm penetration in vitro in the presence of caffeine. $J$. Reprod. Fert. 57, 377-389.

Fukuda, Y. \& Chang, M.C. (1978) The time of cortical 
granules breakdown and sperm penetration in mouse and hamster eggs inseminated in vitro. Biol. Reprod. 19, 261-266.

Jaffe, L.A. (1976) Fast block to polyspermy in sea urchin eggs electrically mediated. Nature, Lond. 261 , 68-71.

Johnson, J.D., Epel, D. \& Paul, M. (1976) Intracellular $\mathrm{pH}$ and activation of sea urchin eggs after fertilization. Nature, Lond. 262, 661-664.

Johnson, M. \& Edidin, M. (1978) Lateral diffusion in the plasma membrane of mouse egg is restricted after fertilization. Nature, Lond. 272, 448-450.

Kazimierczak, W., Peret, M. \& Maslinski, C. (1976) The action of local anaesthetics on histamine release. Biochem. Pharmac. 25, 1747-1750.

Nicolson, G.L. (1976) Transmembrane control of the receptors of normal tumor cells. Biochim. biophys. Acta 457, 57-108.

Niemierko, A. \& Korman, A. (1976) Cytochalasin B induced triploidy in mouse oocytes fertilized in vitro. J. Reprod. Fert. 48, 279-284.

Pollock, E.G. (1978) Fine structural analysis of animal cell surface topography. Am. Zool. 18, 25-69.

Poste, G. \& Allison, A.C. (1973) Membrane fusion. Biochim. biophys. Acta 300, 421-467.

Poste, G. \& Pasternak, C.A. (1979) Virus induced cell fusion. In Cell Surface Reviews, Vol. 5, pp. 306-349 Eds G. Poste \& G. L. Nicolson. North-Holland, Amsterdam.

Schmell, E.D. \& Gulyas, B.J. (1980) Ovoperoxidase activity in ionophore treated mouse eggs. II. Evidence for the enzyme's role in hardening the zona pellucida. Gamete Res. 3, 279-290.
Seeman, P. (1972) The membrane actions of anaesthetics and tranquillizers. Pharmac. Rev. 24, 583-655.

Seeman, P., Chen, S.S., Chan-Wong, M. \& Staiman, A. (1974) Calcium reversal of nerve blockage by alcohols, anaesthetics, tranquillizers and barbiturates. Can. J. Physiol. Pharmacol. 52, 526-534.

. Sheetz, M.P. \& Singer, S.J. (1974) Biological membranes as bilayers couples. A molecular mechanism of drug-erythrocyte interactions. Proc. natn. Acad. Sci. U.S.A. 71, 4457-4461.

Singer, S.J. (1974) The molecular organization of membranes. Ann. Rev. Biochem. 43, 805-833.

Siracusa, G., Whittingham, D.G., Codonesu, M. \& De Felici, M. (1978) Local anaesthetics and phenothiazine tranquillizers induce parthenogenetic activation of the mouse oocyte. Devl Biol. 65 , 531-535.

Surani, M.A.H. \& Kaufman, M.H. (1977) Influence of extracellular $\mathrm{Ca}^{2+}$ and $\mathrm{Mg}^{2+}$ Ions on the second meiotic division of mouse oocytes: Relevance to obtaining haploid and diploid parthenogenetic embryos. Devl Biol. 59, 86-90.

Uehara, T. \& Yanagimachi, R. (1977) Activation of hamster eggs by pricking. J. exp. Zool. 199, 269-274.

Vacquier, V.D. (1975) The isolation of intact cortical granules of sea urchin eggs: calcium ions trigger granular discharge. Devl Biol. 43, 62-74.

Whittingham, D.G., Siracusa, G. \& Fulton, B.P. (1978) Ionic activation of the mammalian egg. Biologie cell. 32, 149-154.

Wolf, D.P. \& Hamada, M. (1979) Sperm binding to the mouse egg plasmalemma. Biol. Reprod. 21, 205-211.

Received 13 May 1981 